\title{
EL SUPUESTO DECLIVE DEL CONSTRUCCIONISMO SOCIAL EN LA PSICOLOGÍA SOCIAL CRÍTICA*
}

\author{
THE SUPPOSED DECLINE OF SOCIAL CONSTRUCTIONISM \\ IN CRITICAL SOCIAL PSYCHOLOGY
}

\author{
Francisco Pavez Correa** \\ ORCID: 0000-0003-4442-9557 \\ Universidad de Chile \\ Santiago-Chile \\ Recibido enero de 2020/Received January, 2020 \\ Aceptado abril de 2021/Accepted April, 2021
}

\begin{abstract}
RESUMEN
El construccionismo social ha sido uno de los grandes aportes de las ciencias sociales a los debates en epistemología, lo que la ha llevado a ser blanco de varias críticas; se la ha acusado de ser irracional, anular la discusión y no permitir el posicionamiento político y ético. Asimismo, los adherentes al construccionismo social plantean que la postura al volverse hegemónica en las ciencias sociales a perdido su capacidad crítica, además de que su énfasis en lo simbólico ha invisibilizado el componente material de las relaciones sociales, por lo que abogan hacia un escenario postconstruccionista que reemplace y actualice a la corriente. Acerca del primer punto, este ensayo desarrollará algunos aspectos del antirrealismo, el relativismo y el nivel ontológico de la construcción con el fin de defender el construccionismo de algunas de las críticas y alejarlo de la caricatura con la que ha sido descrita. Respecto del paso hacia un escenario postconstruccionista lo que se sostendrá es que varios de los planteamientos propuestos por las nuevas teorías ya se encontraban en los postulados del construccionismo social. Todo esto con el objetivo de dar ciertas luces del construccionismo social visto desde la mirada de la psicología social crítica.
\end{abstract}

Palabras Clave: Construccionismo social, Postconstruccionismo, Psicología social crítica, Relativismo, antirrealismo.

\begin{abstract}
Social constructionism has been one of the greatest contributions of social sciences to epistemology debates, which has led to numerous critics; it has been accused of irrational, nullifying the discussion and not allowing political and ethical positioning. On the other hand, supporters of social constructionism contemplate that the position of becoming hegemonic in social sciences have lost their critical capacity, besides that their emphasis on the symbolic has invisibilized the material component of social relations, advocating a post-constructionist scenario, replacing and updating the trend. In the first point, this essay will develop some aspects of anti-realism, relativism and the ontological level of construction in order to defend the constructionism from critics and move away from the cartoon with which it has been described. From the steps toward a post-constructionist scenario, it will be argued that several of the ideas proposed by the new theories were already in the conceptions of social constructionism. With the objective to give ideas of social constructionism analyzed from the perspective of critical social psychology.
\end{abstract}

Key Words: Social constructionism, Post-constructionist, Critical social psychology, Relativism, anti-realism.

\footnotetext{
* Trabajo realizado en el marco del Magíster en comunicación política de la Universidad de Chile. Agradecimientos CONICYT por su financiamiento.

**_Autor correspondiente / Corresponding author: fco.pavez008@gmail.com
} 


\section{INTRODUCCIÓN}

Es innegable la influencia del construccionismo social en el campo de las ciencias sociales, se ha instalado como un enfoque propio de este ámbito capaz de dialogar y debatir acerca de la posibilidad del saber, la verdad y la realidad, problemas cuyo dominio ha sido territorio hegemónico de la filosofía. En palabras de Íñiguez (2005) el construccionismo social es "quizás la única corriente que se ha erigido como uno de los interlocutores en los debates contemporáneos de la Filosofía y de las Ciencias Sociales" (p. 1), convirtiéndose en un marco interpretativo relevante, no solo para la investigación social, sino también para la epistemología. Es particularmente en psicología social donde el construccionismo se instaló con mayor fuerza, ya que trajo consigo ideas frescas a un campo del saber que pasaba por una importante crisis disciplinar (Ibáñez, 2001a; Ema y Sandoval, 2003).

Si bien no hay una definición precisa de lo que es el construccionismo social (Piper, 2008), al menos en psicología social crítica se pueden identificar algunos ejes comunes que son los siguientes: una problematización respecto de la posibilidad de encontrar certezas en la realidad social; una propuesta de superación de la dicotomía sujeto/objeto; una acentuación del componente relacional y social en la producción de conocimiento; la afirmación del carácter construido de la realidad; un fuerte énfasis en la dimensión simbólica de la realidad; y su hincapié en la condición inherentemente histórica y política de los procesos sociales (Ibáñez, 2001a; Burr, 2002; Fernández, 2006).

Estos elementos se insertan derechamente en los históricos debates epistemológicos, por lo que no es extraño que tales ideas se enfrenten con las de otras perspectivas, siendo blanco de cuestionamientos y tensiones, no solo de sus adversarios, sino también de sus adherentes.

La crítica más común es al carácter antirrealista y relativista de sus postulados: la realidad al ser un producto humano que se encuentra supeditada a las diferencias sociales e individuales implica la imposibilidad de enunciar lo verdadero, porque no existiría ningún fundamento para su sostenimiento. Esto conlleva a igualar la validez de cualquier discurso y saber, constituyéndose así una especie de "muerte del debate" que trae consigo tanto la parálisis política como ética, en tanto no se podría plantear qué es lo justo, violento $\mathrm{u}$ opresivo, pues estos apelativos dependen del punto de vista de quien los emite (Blanco, De la Corte y Sabucedo, 2018).

Por otro lado, dentro de sus mismos adherentes se plantea que el construccionismo social al hacerse hegemónico dentro de las ciencias sociales ha perdido su potencial crítico, adquiriendo un carácter conformista, al mismo tiempo que su excesivo énfasis puesto en lo simbólico ha invisibilizado el componente material de las relaciones sociales (Íñiguez, 2005). Por esto para Íñiguez es necesario abrirse a un escenario postconstruccionista que actualice a la psicología social para que esta no pierda su estatus de discurso crítico.

En relación con la crítica de sus adversarios, lo que se desarrollará en este ensayo será una revisión de los sentidos en que el construccionismo social es antirrealista y relativista, como del nivel ontológico de la construcción, de manera de dar algunas luces de sus postulados para alejarlos de la caricatura con la que se la suele asociar. De lo planteado por sus adherentes, lo que se propondrá es que varios de los planteamientos postulados por las perspectivas postconstruccionistas ya se encontraban en el construccionismo social, de aquí que no exista una ruptura radical, sino más bien una continuación en los aspectos menos desarrollados de la perspectiva. Esto conllevará a la revisión y comparación de los aportes asociados al postconstruccionismo.

\section{REALISMO/ANTIRREALISMO, RELATIVISMO Y DIMENSIÓN DE LA CONSTRUCCIÓN}

Para Rorty (1996), el debate realismo/antirrealismo suele ser ambiguo, debido a que lo que se define por antirrealismo suele ser bastante amplio. Para el autor el problema versa más bien sobre el representacionismo y el antirrepresentacionismo, ya que la cuestión sobre el antirrealismo solo tiene sentido para un representacionista, es decir, para alguien que postula que los enunciados se pueden juzgar en función de si "corresponden" o "representan" los hechos y la realidad. El problema del representacionismo es que no se puede acceder a la realidad independientemente del conocimiento que tengamos de ella, es decir, no se puede salir de la experiencia para ver si coincide nuestras representaciones con la realidad. Rorty se posiciona desde el antirrepresentacionismo y sostiene que hay que abandonar las ideas de representación y de correspondencia de nuestros enunciados con la realidad: 
El antirrepresentacionalista concede de buen grado que nuestro lenguaje, como nuestro cuerpo, ha estado modelado por el entorno en que vivimos. En realidad, insiste en esta idea -la idea de que nuestra mente o nuestro lenguaje no podría estar (como teme el representacionalista escéptico) «fuera de contacto con la realidad», como tampoco podrían estarlo nuestros cuerpos-. Lo que niega es que es útil desde el punto de vista explicativo elegir entre los contenidos de nuestra mente o nuestro lenguaje y decir que este o ese elemento «corresponde a» o «representa» el entorno de un modo que no se da en otros elementos (Rorty, 1996, p. 20-21).

De igual manera, los antirrepresentacionalistas consideran como un pseudoproblema la cuestión sobre si la realidad determina el pensamiento o si el pensamiento determina a la realidad. Un realista defendería lo primero y consideraría lo segundo como irracional, sin embargo para Rorty "no es más verdadero que «los átomos son lo que son porque utilizamos 'átomo' como lo utilizamos» que «utilizamos 'átomo' como lo utilizamos porque los átomos son como son»" (1996, p. 20), por lo que ambas afirmaciones carecen de sentido.

El problema de estas discusiones, plantea este autor, está en asumir la idea de que la mente refleja la realidad como un espejo, cuando, más bien, los conocimientos son creencias que corresponden a adaptaciones al entorno por parte de un organismo que interactúa con él mediante su lenguaje y cuerpo, como hábitos o modos de acción (Rorty, 1995).

Ahora bien, desde la psicología social, Ibáñez (2001b) distingue entre realismo ontológico y realismo epistemológico. El primero plantea que la realidad existe independientemente de nosotros; independiente de si la conocemos, la observamos o existimos. Mientras que el realismo epistemológico sostiene que podemos acceder a esa realidad y por tanto tener un conocimiento preciso y certero sobre ella. El realismo epistemológico implica al primero, pero no al revés. El pensamiento mayoritario en ciencia y filosofía acepta el realismo ontológico, pero el realismo epistemológico suele ser puesto en duda, ya que es difícil comprobar que conocemos tal como es el mundo. Ibáñez (2001b) piensa que uno de los problemas que causa confusión en el debate del realismo/antirrealismo es que no se diferencia el problema del "ser" con el de la realidad, "No hay problema alguno para admitir que el ser es y que, además, el ser antecede necesariamente al conocimiento del ser" (p. 17). En este sentido, los antirrealistas no tienen problemas en admitir la existencia del ser, la discusión es más bien sobre los "modos" de ese ser, la forma de la realidad, sus contenidos y características; en definitiva, presentar la realidad como externa, independiente y anterior a los sujetos. Son estas cualidades a las que un antirrealista se opone.

En el caso de Ibáñez (2001b), este intenta hacer una crítica no solo al realismo epistemológico, sino específicamente al ontológico, por medio de una arriesgada exposición de ciertos fenómenos en física cuántica y que en alguna medida muestran que incluso en la realidad natural parece imposible sostener la independencia entre los objetos de estudio y los observadores. Esta es principalmente la tesis del construccionismo social, la realidad no es externa, anterior y por tanto independiente de quien la conoce; si el sujeto de conocimiento cambia, la realidad también cambia y viceversa. Es decir, se postula una relación de interdependencia mutua, lo que implica que la realidad no es ajena a nuestras prácticas, ni nuestras prácticas son ajenas a la realidad. Esto no significa que se puede hacer de la realidad lo que la voluntad quiera, pues la relación con el mundo está limitada tanto por nuestra estructura como por la del mundo -entonces solo podemos mediar con lo que la relación nos permite mediar-, pero estos límites no son naturales y fijos, sino que se presentan como marcos de posibilidades donde, en la relación con el mundo, estos se pueden ampliar o reducir. A modo de ejemplo, para la mentalidad medieval probablemente era ficticio que un ser humano tuviese la capacidad para volar en la realidad, sin embargo esto se ha hecho posible en la actualidad. En este sentido se plantea que, si bien la realidad en tanto interdependiente con nosotros es construida, lo que se construye o no depende del marco histórico-social en el que nos desenvolvemos, de las condiciones materiales y culturales del mundo, que no son sinónimo de naturales y ahistóricas.

El relativismo ha sido quizá el mayor punto de discordia hacia el construccionismo social. Se ha interpretado que si algo depende del punto de vista esto implica necesariamente que cualquier opinión es legítimamente válida, como una especie de "todo vale". Para Ibáñez (2001b) el relativismo es contrario del absolutismo, en tanto lo absoluto es lo que "no depende de nada" y lo relativo es lo 
que "depende de". El relativismo se postula como una perspectiva antiesencialista que cuestiona la idea de un fundamento último, pero no plantea que cualquier cosa es posible, solo dice que lo que se postula depende de las condiciones históricas, sociales, subjetivas, individuales, contingencias, etc. Los relativistas precisamente sostienen la necesidad de hacerse cargo de estas dependencias, por lo que el relativismo no anula el debate, ni destruye el posicionamiento ético, sino que lo reafirma, porque implica que hay que hacerse responsable de las consecuencias de nuestras prácticas, discursos y los valores contenidos en ellos. El relativismo no niega el carácter instrumental o pragmático del conocimiento, es decir, no niega la justificación de ciertos postulados, sino que cuestiona la idea de verdad en tanto certeza absoluta. Rorty lo expone de la siguiente manera:

El epíteto tradicional que los realistas imponen a los pragmatistas es el de "relativismo". Este nombre designa comúnmente tres concepciones diferentes. La primera es la concepción según la cual una creencia es tan buena como cualquier otra. La segunda es la idea de que "verdadero" es un término equívoco, que tiene tantos significados como procedimientos de justificación existen. La tercera es la concepción de que no puede decirse nada sobre la verdad o la racionalidad aparte de las descripciones de los procedimientos de justificación conocidos que una determinada sociedad -la nuestra- utiliza en uno u otro ámbito de indagación. El pragmatista sostiene la tercera concepción, etnocéntrica. Pero no suscribe la primera tesis, que se refuta a sí misma, ni la excéntrica segunda tesis. Piensa que sus ideas son mejores que las de los realistas, pero no cree que correspondan a la naturaleza de las cosas (1996, p. 42).

Es curioso al respecto que algunos autores como Gould (2007) o Donna Haraway (1995) muestran en sus trabajos cómo los conocimientos de la biología de ciertos periodos son frutos de los prejuicios de los investigadores de un determinado contexto histórico, sin embargo se niegan rotundamente a plantear el relativismo en la ciencia. Particularmente en el caso de Haraway y su epistemología feminista, la autora desarrolla, precisamente para contrarrestar por un lado al relativismo y por otro la verdad como certeza absoluta, la idea de los conocimientos situados: hay objetividad, pero esta no es natural, sino que está determinado por nuestros cuerpos y el contexto histórico-social, no como una verdad trascendental ni universal, sino más bien parcial, lo que implica que el conocimiento es objetivo en cierto contexto, bajo ciertas condiciones y ciertos parámetros. Es interesante esta postura, porque es precisamente lo que plantean los relativistas.

Hasta ahora parece no haber realmente algún pensador serio que postule la idea del relativismo como la noción sobre que cualquier declaración es tan válida como las otras. Ni siquiera el mismo Feyerabend (2005), quien desarrolló el pluralismo metodológico precisamente para paliar los límites que tienen las prácticas de producción de conocimiento, ya que no hay un método universal que permita un saber total de la realidad. Otros problemas distintos son la inconmensurabilidad o la traducción de los lenguajes o paradigmas, pero el relativismo no postula irresponsablemente que cualquier opinión es válida por sí misma, sino que tales cuestiones dependen de ciertos escenarios y condiciones de las cuales hay que indagar y hacerse responsable.

Debido a lo anterior se podría plantear que los adversarios del construccionismo social han discutido con una imagen simplificada de la perspectiva y que incluso han defendido lo que los relativistas postulan. El mismo Hacking (2001) -probablemente el crítico más estudioso del construccionismo- acepta que no es una postura irracionalista ni teme en decir que está de acuerdo en parte con lo que se postula. Entonces ¿por qué resulta una corriente tan controversial? Se podría decir que esto se debe a que en reiteradas ocasiones se suele interpretar desde una lógica individualista y localista los postulados del construccionismo social. El mejor ejemplo de esto es Searle (1997) quien plantea que uno de los errores del construccionismo social es no saber diferenciar lo epistemológico de lo ontológico en los enunciados, ni tampoco la diferencia entre las entidades cuando son objetivas o subjetivas. La exposición de Searle sería más o menos como la siguiente:

- Hay un sentido epistémico de la diferenciación objetivo-subjetivo:

- Hay enunciados epistemológicamente objetivos cuando su verdad o falsedad es independiente de los sentimientos o actitudes que uno puede tener sobre ellos. Ej: Piñera es el actual Presidente de Chile. 
- Hay enunciados epistemológicamente subjetivos cuando su verdad o falsedad depende de sentimientos, actitudes y puntos de vista de los hablantes. Ej. Piñera es el Presidente más cómico de Chile.

- Hay un sentido ontológico de la diferenciación objetivo-subjetivo que tiene que ver con los modos de existencia de los entes:

- Hay entidades objetivas que no dependen de la percepción o estado mental. Ej: Piedras.

- Hay entidades subjetivas que dependen de la percepción o estado mental. Ej: Dolores.

Esto le permite a Searle plantear que "Podemos ver claramente la distinción entre distinciones si reflexionamos sobre el hecho de que podemos formular enunciados epistémicamente subjetivos sobre entidades que son ontológicamente objetivas $\mathrm{y}$, análogamente, podemos formular enunciados epistémicamente objetivos sobre entidades que son ontológicamente subjetivas" (1997, p. 28). A modo de ejemplo, podemos decir que el papel verde que dice "mil" y representa mil pesos chilenos es un enunciado epistemológicamente objetivo de un ente ontológicamente subjetivo. Además, Searle agrega a estas clasificaciones las ideas de rasgos intrínsecos de las entidades -vale decir que no dependen de ninguna actitud de los observadores- y rasgos relativos al observador-que dependen de la actitud de los observadores-. La masa de un destornillador es un rasgo intrínseco de la entidad, pero su uso y su categoría de "destornillador" es relativo al observador y por tanto ontológicamente subjetivo, aunque se puede decir que es un mal destornillador, lo que es epistemológicamente subjetivo. Con esto Searle puede defender el realismo y decir que "El monte Everest existe independientemente de si yo o cualquier otro me lo represento y de cómo me lo represento (o de si me represento y cómo me represento cualquier otra cosa)" (1997, p. 162).

¿Cuál es el problema de esto? Es que Searle entiende tanto la relación de los sujetos con la realidad como el carácter construido de la realidad de forma individualista. A esto nos referimos cuando hablamos del nivel ontológico de la "construcción". El construccionismo social tiene la palabra "social" no por mero capricho, sino porque indica el nivel de construcción. Hay que recordar que el construccionismo social pone a la relación (Gergen,
2007) como objeto de su estudio y no al individuo, lo que significa que la relación está en la primacía ontológica de la realidad (Pérez, 2013). Es decir, no hay objetos y luego relaciones, sino relaciones que producen objetos, como bien lo muestra Mead (1982, p. 122):

\begin{abstract}
Si aparece en el mundo un animal que puede digerir hierbas, como un buey, entonces la hierba se convierte en un alimento. Ese objeto, es decir el pasto en cuanto alimento, no existía antes. El advenimiento del buey presenta un nuevo objeto. En ese sentido, los organismos son responsables por la aparición de series enteras de objetos que no existían antes. La asignación de significación al organismo y al medio tiene su expresión en el organismo así como en la cosa, y dicha expresión no es una cuestión de condiciones psíquicas o mentales. Existe una expresión de la reacción de la respuesta organizada del organismo al medio, y tal reacción no es simplemente una determinación del organismo por el medio, puesto que aquel determina a este tan absolutamente como este determina a los órganos. La reacción orgánica es responsable de la aparición de toda una serie de objetos que no existían antes.
\end{abstract}

Tanto el buey como la hierba son producto de la relación que las antecede. Precisamente lo social en el construccionismo social hace referencia a esta idea. El problema está en que pensadores como Searle asumen un individualismo ontológico con el que conciben lo social como una suma de individuos (Venables, 2016). Sin embargo, el estatus ontológico de la relación ya estaba presente en la crítica hegeliana al individualismo atómico de Hobbes (Dri, 2006), en la idea común de Marx y Mead de la conciencia como producto de lo social, o en el desarrollo de la estadística en sociología (Hackings, 1991). Es decir, esta idea es un fundamento aceptado para gran parte de la filosofía y las ciencias sociales, sin embargo, algunos críticos del construccionismo social parecen no estar al tanto de ella. En este sentido, Searle entiende la construcción social desde un nivel local (el individuo), mientras que el construccionismo social plantea la construcción en un nivel global (la relación o lo social). Esto explicaría que se asocie a la perspectiva con una especie de solipsismo que entiende a la construcción social como algo local y voluntario. 
Sin embargo, para Blanco, de la Corte y Sabucedo (2018, p. 1):

La verdadera aportación del construccionismo social ha consistido en suprimir la experiencia como fuente del conocimiento y de la subjetividad, negar la existencia de una realidad externa al sujeto, mantenerse ontológicamente mudo frente a ella y desconfiar de la posibilidad de cambiarla.

Por esto estos autores defienden una psicología social crítica no construccionista para remediar tales problemas. El inconveniente es que el construccionismo social no niega la experiencia como fuente de conocimiento, lo que niega es que se pueda salir por fuera de ella para compararla con la realidad; no desconfía de la capacidad de transformación de la realidad, por el contrario, la interdependencia de ella con nuestras prácticas permite su transformación; tampoco niega, como los autores plantean, la violencia: un construccionista social plantearía que como la violencia es producto de las relaciones de opresión que sostenemos podemos cambiar las condiciones de su posibilidad.

La pregunta que se puede hacer al respecto -para precisar más aún la cuestión del nivel de la construcción- es que, cuando hablamos de realidad externa, esta ¿a qué es externa?, ¿a lo social?, ¿a la humanidad?, ¿al individuo? Para un construccionista social puede ser perfectamente aceptable plantear que un edificio es externo al individuo, en el sentido de que si, por ejemplo, el autor de este ensayo muere, el edificio seguirá existiendo, ya que el construccionismo social no es solipsista. El edificio es precisamente el mejor ejemplo de construcción social, ya que se construye materialmente, por obreros, trabajadores e ingenieros que hacen uso de un saber producido históricamente. Los construccionistas sociales no plantean que la violencia o la opresión al ser construcciones sociales sean falsas, sino por el contrario, son reales, y precisamente como son históricas se pueden transformar. Hay que entender a la perspectiva desde la dimensión que propone, que es la dimensión social. Para un construccionista social la realidad puede ser externa al individuo, pero no a la humanidad.

Ahora bien, alguien podría argumentar que los edificios efectivamente son construcciones sociales en tanto no hay edificios sin humanos, pero ¿qué pasa con las montañas? la naturaleza claramente es anterior y exterior a la humanidad. Ciertamente el construccionismo social asume cierta postura "agnóstica" sobre la naturaleza. Es decir, siguiendo a Mead (2008), el pasado y el futuro son instancias que se encuentran dentro del presente, un presente que es siempre un dejar de ser, pero que es todo el tiempo. ¿Qué quiere decir esto?, que la naturaleza es algo con lo que nos relacionamos e interactuamos ahora, en nuestra experiencia presente. Pero como no sostenemos una postura solipsista, postulamos que la naturaleza se encuentra en la totalidad de la experiencia humana, es decir, en todo el tiempo desde que hay humanos. Decir que la naturaleza existió antes que la humanidad es difícil de sostener, tenemos grandes motivos para creer que un Big Bang creó el tiempo y el espacio, pero plantear que esto fue así sin que alguien haya estado ahí presente, es para Pérez (1998) un ejemplo de dogmatismo. Los dinosaurios o el universo parecen ser anteriores a la historia humana, pero es la misma historia humana quien a partir de su relación con la naturaleza presente lo postula así. Esto es una especie de postulado agnóstico sobre la naturaleza, porque en la medida que no se puede salir de la experiencia de la humanidad, no tiene sentido plantear la existencia anterior e independiente de la naturaleza, o más bien, no es relevante para nuestro conocimiento si esta es anterior o no a la humanidad. Otra forma de abordar esto es seguir cierta interpretación hegeliana donde la sustancia es también sujeto, y por tanto la naturaleza un ente agencial que se relaciona consigo mismo y donde la humanidad es producto de esta autorrelación. En este sentido lo social y lo natural son falsas dicotomías, porque hay una continuidad entre ellas. Pero claramente tales cuestiones están en un nivel de especulación filosófica que escapan de lo que se desea abordar en este apartado.

Lo que intentamos dilucidar en esta parte fue el sentido en el que el construccionismo social es antirrealista y relativista, aclaramos la dimensión de la construcción y finalmente sostuvimos que muchas de las críticas que ha recibido son debidas a lecturas individualistas de la perspectiva, como a que no se entiende del todo bien qué implica posicionarse como antirrealista y relativista. Lo que prosigue en el siguiente apartado es la revisión de la crítica interna que ha recibido el construccionismo social. 
CONSTRUCCIONISMO SOCIAL, PSICOLOGÍA DISCURSIVA Y POSTCONSTRUCCIONISMO

Según Íñiguez (2005) el construccionismo social se convirtió en una postura acomodadiza que, al volverse hegemónica en la academia, perdió su potencial crítico. Sin embargo, no parece ser un destino necesario tal resultando, pues él mismo plantea que para seguir sosteniendo el componente crítico en la psicología social es necesario retener algunos elementos del construccionismo social y problematizar otros, de manera de abrir un espacio hacia una mirada postconstruccionista. Para ello es necesario interiorizar los aportes y las críticas de las perspectivas actuales como la teoría de la actor red, de la performatividad y las epistemologías feministas. Lo que sostenemos es que varios de los elementos afirmados por estas teorías ya estaban postuladas en los construccionismos sociales. A nuestro modo de ver, el problema se relaciona con la identificación del construccionismo social-sobre todo en psicología - con la psicología discursiva, y esta última, a pesar de incluir los elementos performativos de los actos del habla, en su desarrollo ha puesto el énfasis en las características interpretativas y hermenéuticas de los discursos, vinculando el construccionismo social principalmente con los fenómenos del campo de lo simbólico.

El primer aporte del escenario postconstruccionista que describe Íñiguez (2005) viene desde la teoría de actor red (ANT) desarrollada en el campo de la sociología del conocimiento, cuya importancia radica en su intento de superar las dualidades comunes a las ciencias sociales tales como lo social/natural, discurso/materialidad, humano/ no humano, a partir de la idea que la agencia no es exclusiva de los seres humanos, sino también de actantes no humanos.

Desde esta perspectiva no hay distinción entre actriz y contexto o actriz y escenario, y no es posible la repetición, como sucede en la Teoría de la Performatividad, sino que cada iteración genera diferencia. El valor, el sentido, de cualquier elemento depende de los otros con los que se relaciona y la cuestión estaría en estudiar cómo las entidades se co-construyen las unas a las otras (Flores-Pons, Íñiguez-Rueda y Martínez-Gúzman, 2015, p. 204).

Quizá se pueda encontrar un antecedente de una materialidad agencial en Hegel (1966) cuando habla de la sustancia viviente, pero resulta más interesante mostrar que es el mismo Mead (2008) quien en psicología parece ya haber planteado la agencialidad de entidades no humana cuando escribe lo siguiente:

Agarrar un objeto sólido es autoestimularse a ejercer ese esfuerzo interior. Uno suscita en sí mismo una acción que también proviene del interior de la cosa, porque la experiencia incrementa la acción de otros cuerpos sobre los organismos y sobre otras cosas que están en el mundo perceptivo. El objeto del organismo suscita en el organismo la acción del objeto sobre este, y de esa manera viene a estar dotado de esa naturaleza interior de presión que constituye el interior de la cosa física. Solo en la medida en que el organismo, de esa manera, toma la actitud de la cosa, adquiere esta un interior (p. 303-304).

Es decir, en la aprehensión de los objetos, su resistencia a nuestra manipulación cumple un rol fundamental ya que es a partir de ahí que podemos interiorizar la actitud de los objetos. Luego resulta comprensible cuando Mead afirma que los ingenieros tienen que dialogar con la naturaleza para construir un puente, esto a partir que los ingenieros interiorizan la perspectiva de ese otro no humano. En este sentido el pensamiento de Mead posee un cierto animismo destacable en la medida que concibe un enfoque material sobre lo mental como alternativa a la idea de que este es lo que hay dentro de la cabeza de un individuo (Fernández, 1994). En este sentido se puede decir que es en "Mead donde hallaremos la formulación más acabada de una Psicología Social de los objetos" (Doménech, Íñiguez y Tirado, 2003, p. 22). Esto también está en completa sintonía con lo planteado por la sociología del conocimiento. Al igual que en Mead, para Pickering (1984) la naturaleza opone resistencia a nuestro intento de producir conocimiento científico sobre ella. Es a partir del trabajo de articulación con la tecnología y los medios disponibles que se puede intervenir en la naturaleza para obtener resultados, pues esta no es meramente pasiva.

El construccionista cree que fueron posibles muchos ajustes robustos, aunque al final solo uno parece concebible. De hecho, el ajuste a que se llega es contingente. La física no tenía por qué desarrollarse siguiendo la vía de los quarks. Esto no es debido a que los físicos, 
mediante algún acto de decisión colectiva, pudieran haber elegido conscientemente una descripción del mundo más que otra. No se encontrará en la obra de Pickering tan quimérico libertarismo. La afirmación que hace es que hay diferentes formas de adaptarse a la resistencia, que implican no solo pensamiento, sino también fabricar diferentes tipos de aparatos y muchas formas de penetrar y adaptarse al mundo material resultante (Hackings, 2001, p. 126-127).

Es decir, un contexto diferente permite un acceso distinto a los fenómenos que posibilita, en este sentido se podría producir una física diferente y aun así exitosa. En Latour y Woolgar (1995) también nos encontramos con una perspectiva similar. En sus trabajos sobre el laboratorio concluyen que el descubrimiento de la hormona TRH fue un proceso donde se forzó prácticamente la aparición de esta: ya que la hormona en estados naturales era indetectable, los científicos tuvieron que acumular una cantidad enorme de cerebros de cerdo para lograr su identificación y posterior síntesis. Debido a que la naturaleza no es pasiva y se resiste a las intervenciones humanas, es que se han formulado perspectivas como la ANT.

Es curioso que Hacking (2011) sitúe a la sociología del conocimiento de Pickering, Latour y Woolgar dentro de la perspectiva construccionista e Íñiguez los remita al postconstruccionismo. También es interesante la recepción de Mead en la misma psicología social, autor que ha sido muchas veces situado como un precursor del socioconstruccionismo, y que como vemos desarrolla anticipadamente ideas similares a las mencionadas, a pesar de que es mayormente conocido como un antecedente del interaccionismo simbólico. Esto último es relevante porque parece ser que, al menos en psicología social, hay dificultades para entender la construcción social desde un punto más allá de lo simbólico.

La otra gran teoría que se despliega como aporte a un escenario postconstruccionista es la de la performatividad en la teoría queer. Butler (2006) retoma las ideas desarrolladas por Austín para analizar el género y la materialidad del cuerpo. La performatividad

Además, ha sido una noción que ha permeado muchos ámbitos de estudio, de modo que son diferentes las apropiaciones que se han hecho de ella. Sin embargo, quizás sí podamos decir que la propuesta de Butler enfatiza que la repetición de los enunciados es un elemento clave para producir un efecto de poder donde el discurso se materializa en los cuerpos, identidades y vidas, conformando subjetividades de género y experiencias corporeizadas (Flores, Íñiguez y Martínez, 2015, p. 203).

Para Flores, Íñiguez y Martínez, particularmente la idea de los actos ilocutivos de Austin y los desarrollos de la performatividad en la Teoría Queer, son los insumos teóricos que permiten superar la dicotomía entre discurso y materialidad, los que son además la base del análisis del discurso. Particularmente este último se ha convertido en la perspectiva metodológica central en la psicología discursiva.

Los orígenes tanto de la psicología discursiva como del análisis del discurso son variados; han recibido influencias de la filosofía analítica, de la semiótica, la etnometodología, la lingüística, el postestructuralismo y la hermenéutica. A grandes rasgos, la psicología discursiva entiende los procesos psicológicos en el marco de los discursos, y estos, siguiendo a Íñiguez y Antaki (1994), son "un conjunto de prácticas lingüísticas que mantienen y promueven ciertas relaciones sociales" (p. 63). Es interesante la caracterización sobre el discurso como "prácticas lingüísticas", ya que el componente práctico tiene el germen de lo material en el discurso, pero lo "lingüístico" puede hacer referencia a dos cuestiones distintas: a) que las prácticas materiales también son simbólicas y viceversa, por tanto la dicotomía semiótico/material no se sostiene; o b) que si hay prácticas lingüísticas, habrían otras no lingüísticas y el análisis del discurso solo se preocupa de las primeras y deja de lado las segundas. Parece ser que Íñiguez (2005) se posiciona desde la segunda concepción, por ello valora de la teoría de la performatividad de Butler el abordaje de las prácticas no lingüísticas. Pero aquí es mucho más problemático plantear estas concepciones dentro de un escenario postconstruccionista, ya que a diferencia de lo material agencial que vimos anteriormente, acá la continuidad es más directa. $\mathrm{La}$ psicología discursiva parte de los desarrollos de Austin sobre los actos de habla que, junto con los juegos del lenguaje de Wittgenstein, son la base de la pragmática en lingüística que es lo que el análisis del discurso toma como referente (Sandoval, 
2004). Hay una relación directa entre la psicología discursiva y la teoría de la performatividad, aunque se puede aceptar que en esta última hay un mayor énfasis en el componente material del discurso. A nuestro modo de ver, más que dar pie a un escenario postconstruccionista da cuenta de la evolución del construccionismo social hacia elementos que habían sido menos desarrollados.

Entonces habría que hacerse la pregunta ¿por qué ha habido una preponderancia de lecturas puestas en lo simbólico en el construccionismo social en psicología social? La respuesta puede ser que, en el desarrollo de la historia de la psicología social, lo simbólico es lo que le ha dado cierto estatus disciplinar y autónomo. A pesar de que el socioconstruccionismo no es una corriente exclusiva de la disciplina, es en ella donde parece haberse desarrollado con mayor fuerza. En su historia desde un enfoque más conductista puesto en la teoría de las actitudes, luego el giro cognitivo y la idea de las representaciones sociales, para finalmente con la influencia del construccionismo social terminar en el estudio de los discursos, puede apreciarse la constancia de lo simbólico en su devenir. Si para Brunner (1995) la importancia del giro cognitivo fue haber hecho plausibles el estudio y la relevancia de los procesos de significación, con la psicología discursiva estos procesos se ampliaron de lo cognitivo o representacional hacia la esfera de las prácticas sociales. Se puede decir que la psicología discursiva ensancha el campo de estudios de lo simbólico. Y este énfasis, al igual que el énfasis en el interaccionismo simbólico de Mead, opacó o dejó en segundo plano el estudio de las prácticas materiales del construccionismo social. Pero si entendemos la perspectiva, como se ha venido describiendo, como una ontología de la relación, es la relación lo que supera las dicotomías semiótico/material o social/ natural. Y la psicología social, hará más énfasis en la relación social, dado a su objeto disciplinar. Pero hay que entender que la "construcción" en el construccionismo social no es solo simbólica, se da dentro de un marco posibilitado por el contexto histórico-social que incluye a una gran cantidad de elementos, dinámicas y prácticas que no se reducen a lo discursivo entendido meramente como lo lingüístico. A pesar de que Vivien Burr (2015) remarca la gran influencia de las perspectivas discursivas en la constitución de los construccionismos sociales, tampoco se puede identificar psicología discursiva con construccionismo social. Quizá esta identificación es la que ha llevado a autores como Parker (2007) a acercarse al realismo crítico y a distanciar su psicología crítica de la psicología discursiva. Particularmente para dicho autor, las perspectivas discursivas han perdido el interés por los contextos de enunciación, lo que las ha llevado a invisibilizar las relaciones de poder inherentes en los discursos, sucumbiendo ante visiones apolíticas posmodernas. De ahí sus motivos para alejarse de estas perspectivas.

Ahora bien, detengámonos en los aportes de las epistemologías feministas considerados por Íñiguez (2005) también como parte de los insumos que dan cuenta de un escenario postconstruccionista. Particularmente Haraway (1995) y su enfoque sobre los conocimientos situados que se establecen como una crítica hacia la idea de un saber universal y objetivo, pero sin caer en un relativismo descomprometido -como diría García Selgas (1999, p. 165) "caminado por el filo entre el realismo y el relativismo"-. Haraway nos plantea que ningún conocimiento está desligado del contexto en el que se produce ni es independiente de quien lo emite, por ello aboga por hacer explícita la posición desde donde se enuncia el saber, poniendo de manifiesto el posicionamiento político y ético del investigor/a. El sujeto desde este punto de vista se lo concibe como históricamente situado, por lo que su mirada es parcial, pero su conocimiento puede ser objetivo bajo ciertas condiciones y en determinado contexto. $\mathrm{Al}$ respecto es revelador comparar esta visión con las ideas de la acción situada en psicología social socioconstruccionista:

se postula una perspectiva del conocimiento como una forma de acción situada, desde la cual el problema de la relación entre conocimiento y realidad pasaría por la posibilidad de comprender que las prácticas de significación/construcción de la realidad social no transcurren en el vacío, y por lo tanto, estas necesariamente deben ser analizadas en un contexto que adquiere sentido desde un cúmulo de relaciones sedimentadas como corporalidad y forma de vida. Desde esta perspectiva del conocimiento como acción situada, los procesos de significación -o construcción psicosocial del sentido- siempre estarían situados en un trasfondo semiótico-material en el cual se articulan saberes y disposiciones corporales, con normas y tradiciones que hacen parte de una forma de vida (Sandoval, 2006, p. 135-136). 
Ciertamente la idea de un conocimiento situado es un punto común entre las epistemologías feministas y el construccionismo social.

Donde se escapa el pensamiento de Haraway del construccionismo -y hay que agregar aquí al de Latour también- es quizá en la radicalidad de su posthumanismo. En La promesa de los monstruos (Haraway, 1999) la autora nos habla que lo colectivo está constituido por una interfaz humano/no humano/no máquina, una agrupación de diferentes actantes que aparecen en la escena social; artefactos, máquinas, animales que dejan de ser considerados como meros objetos pasivos ante la intervención humana y pasan a ser parte activa y agentes en lo social. Esta mirada no debería sernos ajena, sobre todo cuando observamos que, por ejemplo, en la protesta social no solo hay participación de humanos, sino perros que acompañan la movilización, cámaras que graban lo sucedido y una gran cantidad de objetos lanzados -como las piedras, que se hacen las protagonistas de la resistencia popular-.

Si comparamos esta visión de lo social y su énfasis en lo no humano con la visión clásica del construccionismo social -que en tanto sostiene la imposibilidad de separar la realidad de la experiencia humana sitúa precisamente en el centro de lo social al componente de lo humano- resulta que el construccionismo social es una perspectiva mucho más humanista. Pero aquí entra en juego la visión que se tiene tanto de lo que significa el humanismo como de lo que se entiende por posthumanismo. Pues si seguimos a García Selgas (2008) existen diferentes nociones sobre el humanismo y diferentes críticas hacia tales nociones, lo que también implica diferentes perspectivas a las que se podría denominar posthumanistas. Por ejemplo, García Selgas habla del antihumanismo de Althusser, con su intento de separar lo científico de la filosofía especulativa dentro del marxismo mediante el énfasis en la sobredeterminación de las estructuras económicas y sociales -visión que culminó en su reverso, el humanismo, al plantear la consolidación extrema de la razón-; de la visión heideggeriana que considera la tecnología como una especie de prótesis humana que permite transformar el mundo a nuestra propia imagen -equiparando humanismo con tecnología-; y el posthumanismo contemporáneo que considera a la tecnología como un actor que, más que ser una mera extensión del ser humano, establece límites y desplaza al ser humano del centro de la reflexión. En este sentido, lo que caracteriza al posthumanismo sería un rechazo al universalismo abstracto, el cuestionamiento a la centralidad del ser humano como sujeto de la historia y la ruptura de las dualidades de la modernidad (García Selgas, 2008).

Es aquí donde se complican las cosas, pues tales cuestionamientos del posthumanismo se podrían considerar como parte de varios movimientos intelectuales. Y es que, si consideramos como humanismo a la idea de un individuo como un yo racional, libre y coherente, que domestica el mundo por medio de la razón, resulta que tal visión se ha erosionado desde hace bastante tiempo. Ya el idealismo alemán problematizó la idea de una subjetividad meramente individual, el psicoanálisis a la noción del sujeto consciente, la piscología misma ha criticado la idea del yo coherente, el marxismo planteó que las relaciones sociales enmascaraban relaciones de explotación, la historiografía de la ciencia cuestionó la idea de la evolución racionalista de la misma, el descentramiento del sujeto de las visiones estructuralistas y postestructuralistas, el pragmatismo norteamericano que intenta superar dualidades como mente/cuerpo, acción/pensamiento, etc. Ciertamente el posthumanismo se podría considerar como una de las vertientes y quizá la rama más radical de este programa de investigación basado en el desplazamiento del sujeto.

En este sentido, y como bien plantea Burr (2002), si el construccionismo fue influenciado por el antiesencialismo y el antihumanismo de las perspectivas estructuralistas, postestructuralistas y discursivas, el posthumanismo del postconstruccionismo viene a radicalizar y llevar hacia nuevos horizontes a la crítica del construccionismo social. Precisamente es esta la idea que hemos querido plasmar en este apartado; varios de los aportes teóricos con los que se dice que se abre un espacio hacia un escenario postconstrucionista, a nuestro modo de ver, corresponden más bien a nuevas ramificaciones, nuevos desarrollos de gérmenes que se encontraban en el construccionismo social y que ahora pasan a ampliar su esfera. Pues, al final resulta curioso que al hablar de construccionismo social, psicologías críticas o postconstrucionismo se tenga un marco teórico tan similar con menciones a autores tales como Mead, Butler, Haraway, Bergen y Luckman, Latour etc., lo que da cuenta más de lo común a tales perspectivas que de diferencias reales o rupturas radicales. Problema distinto es que la hegemonización de una línea disminuya su potencial crítico, como bien plantea Íñiguez (2005). 


\section{REFLEXIONES FINALES}

En este ensayo intentamos en un primer momento clarificar y explicitar los sentidos en el que el construccionismo social es antirrealista como relativista, al mismo tiempo de mostrar el nivel en el que se efectúa la construcción de la realidad. Sostuvimos que el antirrealismo no implica una postura contra la existencia o realidad del ser, sino el cuestionamiento al modo de ser con el que se la concibe, es decir, como una realidad anterior e independiente de la experiencia humana. También sostuvimos que el relativismo no implica un descompromiso con la realidad, sino por el contrario el posicionamiento de nuestras perspectivas y la obligación de hacerse responsables de los saberes y las prácticas que intervienen en ella. Por último, explicitamos que el construccionismo se debe entender desde la ontología que propone, desde las relaciones y lo social, para evitar miradas individualistas que caigan en solipsismos o idealismos ingenuos.

En un segundo momento revisamos los aportes de ciertas líneas teóricas que han llevado a algunos a plantear la emergencia de un escenario postconstruccionista en psicología social. Al comparar tales líneas sostuvimos que más que demostrar la manifestación de innovaciones teóricas, nos encontramos ante la expansión de varios de los contenidos, algunos invisibilizados por la gran influencia de la psicología discursiva, del construccionismo social. Desde este punto de vista, la teoría ANT, la teoría de la performatividad, los conocimientos situados de la epistemología feminista de Haraway tienen elementos comunes y han influenciado al construccionismo social. Donde sí encontramos mayor divergencia es en la mirada posthumanista con la que trabaja el postconstruccionismo, pero que sostuvimos que en tanto se puede situar como continuadora del proyecto de desplazamiento del sujeto, es una mirada que complementa al construccionismo social al hacer énfasis en los elementos no humanos de las relaciones sociales.

El construccionismo social probablemente seguirá siendo una postura controversial, aun cuando sea hegemónica para parte de las ciencias sociales. Sin embargo, no debe ser reducida, como sus adversarios parecen hacer, a un mero solipsismo; ni tampoco ser identificada con lo discursivo, como incluso sus adherentes parecen haber establecido, solo para proclamar nuevos escenarios intelectuales con el objetivo de mantener la apariencia de novedad tan típica de los tiempos actuales. Tampoco puede carecer de cuestionamientos, pues si el construccionismo social quiere mantener su vigencia y potencial crítico, al igual como ya había argumentado Ibáñez (2001a), debe como Penélope hacer y deshacer los tejidos que va creando en el camino. 


\section{REFERENCIAS}

Blanco, A., de la Corte, L., y Sabucedo, J. M. (2018). Para una psicología social crítica no construccionista: Reflexiones a partir del realismo crítico de Ignacio Martín-Baró. Universitas Psychologica, 17(1), 1-25.

Bruner, J. S. (1995). Actos de significado. Alianza Editorial.

Butler, J .(2006). Deshacer el género. Paidós.

Burr, V. (2002). An Introduction to Social Constructionism. Taylor \& Francis.

Burr, V. (2015). Social Constructionism (3rd ed.). Routledge.

Doménech, M., Íñiguez, L., y Tirado, F. (2003). George Herbert Mead y la psicología social de los objetos. Psicologia \& Sociedade, 15(1), 18-36. https://doi.org/10.1590/S0102-71822003000100003

Ema, J. y Sandoval, J. (2003). Mirada Caleidoscópica al construccionismo social. Política Y Sociedad, 40(1), 5-14. https:// revistas.ucm.es/index.php/POSO/article/view/POSO0303130005A

Fernández, P. (1994). La Psicología Colectiva un fin de siglo más tarde. Su disciplina. Su conocimiento. Su realidad. Anthropos.

Fernández, R. (2006). Investigación cualitativa y psicología social crítica en el Chile actual: Conocimientos situados y acción política [52 párrafos]. Forum Qualitative Sozialforschung / Forum: Qualitative Social Research, 7(4), 38. http://nbn-resolving.de/ urn:nbn:de:0114-fqs0604380.

Feyerabend, P. (2005). Adiós a La razón. Tecnos Editorial.

Flores-Pons, G., Íñiguez-Rueda, L., y Martínez-Guzmán, A. (2015). Discurso y Materialidad: Pensar las prácticas semiótico-materiales. Alpha (Osorno), 40, 201-214. https://doi. org/10.4067/s0718-22012015000100016

García Selgas, F. J. (1999). El Cyborg como reconstrucción del agente social. Política y sociedad, 30, 165-193.

García Selgas, F. J. (2008). Posthumanismo(s) y ciencias sociales: una introducción. Política Y Sociedad, 45(3), 7-15.

Gergen, K. (2007). Construccionismo social: aportes para el debate y la práctica. Universidad de los Andes, Facultad de Ciencias Sociales.

Gould, S. J. (2007). La falsa medida del hombre. Crítica.

Hacking, I. (1991). La domesticación del azar: la erosión del determinismo el nacimiento de las ciencias del caos. Gedisa.

Hacking, I. (2001). ¿La construcción social de qué?. Paidós.

Haraway, D. J. (1995). Ciencia, cyborgs y mujeres: la reinvención de la naturaleza. Cátedra.

Haraway, D. (1999). Las promesas de los monstruos: una política regeneradora para otros inapropiados/ble. Política $Y$ Sociedad, 30, 121.
Hegel, G. (1966). La Fenomenología del Espíritu. Fondo de Cultura Económica.

Ibáñez, T. (2001a). Psicología Social Construccionista. Universidad de Guadalajara.

Ibáñez, T. (2001b). Municiones para disidentes: realidad, verdad, política. Gedisa Editorial.

Iñiguez, L. y Antaki, Ch. (1994). El análisis del discurso en Psicología Social. Boletín de Psicología, 44, 57-75.

Íniguez, L. (2005). Nuevos debates, nuevas ideas y nuevas prácticas en la psicología social de la era 'post-construccionista'. Athenea Digital, 8.

Latour, B. y Woolgar, S. (1995). La vida en el laboratorio: la construcción de los hechos científicos. Alianza Editorial.

Mead, G. (1982). Espíritu, Persona y Sociedad. Desde el punto de vista del conductismo social. Paidós.

Mead, G. (2008). La filosofía del presente. Centro de Investigaciones Sociológicas.

Parker, I. (2007). Psychology. En M. Hartwig (Ed.), A Dictionary of Critical Realism (pp. 390-391). Routledge.

Pérez, C. (1998). Sobre un concepto histórico de Ciencia: de la epistemología actual a la Dialéctica. LOM.

Pérez, C. (2013). Sobre Hegel. (3ra ed.). Santiago, Chile: Creative Commons.

Piper, I. (2008). Socio construccionismo y sus usos en psicología. En A. Kaulino and A. Stecher (Eds.), Cartografía de la psicología contemporánea (pp. 337-348). LOM.

Pickering, A. (1984). Constructing Quarks: A Sociological History of Particle Physics. Chicago UP.

Potter, J. (1998). La representación de la realidad: discurso, retórica y construcción social. Gedisa.

Rorty, R. (1995). La filosofía y el espejo de la naturaleza. Cátedra.

Rorty, R. (1996). Objetividad, relativismo y verdad: escritos filosóficos 1. Paidós.

Sandoval, J. (2004). Representación, discursividad y acción situada. Universidad de Valparaíso.

Searle, J. R. (1997). La construcción de la realidad social. Paidós.

Venables, J. P. (2016). Aportes para una ontología social realista. Cinta de moebio, 56, 172-186. https://doi.org/10.4067/ s0717-554x2016000200005 